\title{
The Nasal Coastline of Traquair's Island: The Influence of Gaze Direction on the Recorded Nasal Visual Field
}

\author{
Hans Callø Fledelius ${ }^{1 *}$ \\ ${ }^{1}$ University Eye Department, Rigshospitalet, 2100 Copenhagen, Denmark \\ *Corresponding Author: Hans Callø Fledelius, University Eye Department, Rigshospitalet, 2100 Copenhagen, \\ Denmark; Email: hcfled@mail.dk \\ Received Date: 28-10-2020; Accepted Date: 28-11-2020; Published Date: 04-12-2020 \\ Copyright $^{\oplus} 2020$ by Fledelius HC. All rights reserved. This is an open access article distributed under the terms \\ of the Creative Commons Attribution License, which permits unrestricted use, distribution, and reproduction in \\ any medium, provided the original author and source are credited.
}

\begin{abstract}
Objective: In a pilot study to evaluate the importance of the nose for the definitive size and shape of the nasal visual field.

Methods: Six eye-healthy individuals aged 12-59 years volunteered for regular bilateral assessment by kinetic Goldmann perimetry, which was compared with recordings performed after changing access from visual space by monocular horizontal shifts of fixation.

Results: Despite increased visual access at lateral fixation the nasal visual span uniformly maintained its size.

Conclusion: Establishing the definitive visual field seems to be part of a toddler's development of full visual function, as apparently based on an interplay between visual input and functional maturation. A scant literature supports it as being close to adult norm already from the age of 6-12 months, and not restricted on its way to full field by periocular facial contours, as often forwarded in literature of the past.
\end{abstract}

\section{Keywords}

Visual Field Borders; Visual Space Restriction by Facial Anatomy; Kinetric Goldmann Perimetry; Lateral Shift of Monocular Fixation; Infants' Visual Field Development 


\section{Introduction}

The visual field always serves us for survival. Objects in space arouse visual attention, and we react accordingly. A reflective turn of visual direction brings the object in focus for maximum resolution and recognition. The normal visual span outwards covers the full temporal field, about $90^{\circ}$, and access for incoming light to the first refractive surface is free of facial structures. For upwards, inwards and downwards gaze, the anterior periorbital anatomy restricts the marginal input of light. Towards the nose, the normal visual field is usually about $60^{\circ}$. Added to visual access, the individual preconditions for establishing visual field are clear imaging and a receptive retina for the refracted full visual input. The photoreceptors convert wavelength energy to visual transmission via propagating electric changes, eventually allowing images and elaboration by the brain.

The retina has cones and rods from the posterior pole to the anterior ora serrata; the resolution decreases towards the periphery. The classical profile of Traquair's Island expresses sensitivity gradients over the seeing retina, as decreasing towards periphery, and recording of large-object suprathreshold stimuli depicts its coastline [1]. The more posterior light-receiving retinal area directly handles the incoming light, whereas the anterior retina towards the ora serrata appears optically out of reach, although theoretically ready for vision or other use.

As regards possible peripheral limitations set by facial contours, within physiological limits there will always be $90^{\circ}$ free temporal gaze even with when deepest set eyes, whereas the bridge of the nose may hinder access to the eye in smaller or larger sectors from that direction. Getting free of the nose by a lateral turn of the eye, the physical size of this input sector would increase.

\section{Methods}

\section{The Experiment}

As a premise, a normal kinetic Goldmann set-up is first scheduled under the approximated theoretical concept of a $60^{\circ}$ nasal field and a $90^{\circ}$ temporal field, as tested with the usual midcentre fixation (Fig. 1). Re-testing after a $25^{\circ}$ turn of fixation towards the nose, the access from the nasal visual space is reduced, whereas the temporal $90^{\circ}$ access is maintained. A corresponding lateral turn of fixation allows extra nasal visual space of $25^{\circ}$, whereas $25^{\circ}$ temporal periphery is lost, simply because the test stimulus is now outside the screen.

Six eye-healthy individuals aged 12-59 years volunteered for the visual field examinations; 4 were ophthalmic staff members and 2 were from the author's family. Informed consent was obtained (from the parents for the 2 teenagers) and the tenets of the Declaration of Helsinki 
were respected. There were no invasive procedures, and data were anonymised. Graph Pad Prism 4 was used for statistics.

Kinetic Goldmann perimetry was recorded for each eye. A suprathreshold object (IV,4e) was used and the initial isoptres recorded with the gaze straight ahead (Fig.1). Next, discreet horizontal fixations marks were added ex centre inside the Goldmann screen, $25^{\circ}$ inwards and outwards, respectively; visual fields were then re-tested accordingly and changes analysed.

\section{Results}

By inwards horizontal $25^{\circ}$ shift of fixation (Fig. 1) the recorded temporal field maintained its primary recorded size, whereas the factual reduction in the nasal field theoretically associated with the bridge of the nose did not quite reach the shift of $25^{\circ}$. By lateral fixation (Fig. 1), the temporal gaze was reduced as expected ("outside screen"); despite increased access, the span of the nasal field was merely maintained, metaphorically also showing no change in the nasal Traquair coastline, despite the more open conditions.

Ten eyes showed acceptable cooperation, and the results appeared uniform. The observations were normally distributed (Graph Pad Prism). The average change for lateral gaze was a reduction of $24.5^{\circ}$ temporally (range, $22^{\circ}-27^{\circ}$, SD 1.57 ), whereas the nasal field maintained its basic span. For nasal field at inwards gaze, the horizontal reductions ranged from $15^{\circ}$ to $18^{\circ}$, with a mean value of $16.2^{\circ}$ and a standard deviation of 1.23 . 

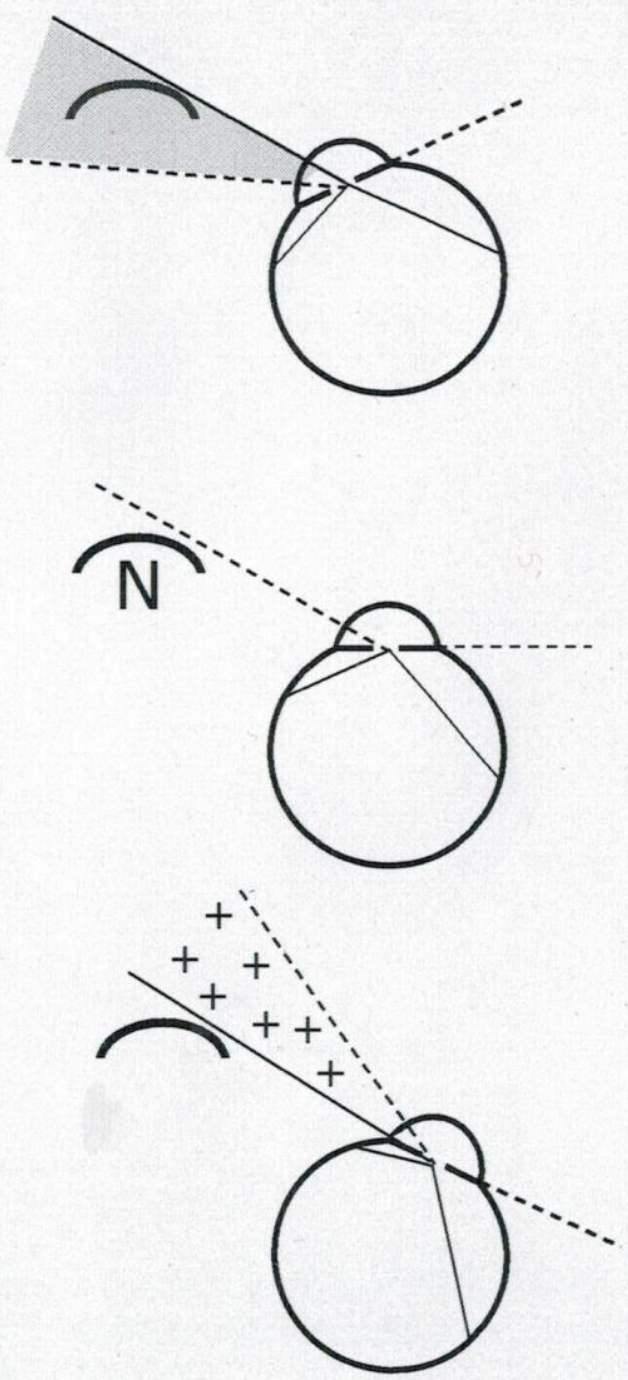

Figure 1: Schematic presentation of the test conditions for large-object kinetic Goldman perimetry, with orderly gaze direction in the middle, and a horizontal $25^{\circ}$ shift in fixation towards the bridge of the nose and temporally, respectively. The hatched area is now hidden by the nose (top), and plus'es denote increased access to nasal visual space (bottom). As a chosen precondition, habitual nasal and temporal visual field borders of $60^{\circ}$ and $90^{\circ}$ from the visual axis were chosen. 


\section{Discussion}

A simple explanation for the lower score for nasal field restriction than the value of $25^{\circ}$ given by the experimental inwards shift of fixation could be that the scheduled $60^{\circ}$ nasal rim obstacle underlying the chosen visual field limit factually is not valid $[2,3]$. With $10^{\circ}$ more towards the periphery actually available for light perception with the gaze straight ahead, the recorded reduction in the visual field associated with the shift in fixation towards the nose would be correspondingly lower. In accord, Lewis and Maurer reported free values in adults ranging from $68^{\circ}$ to $85^{\circ}$ until factual "shadowing" by the nose [3]. Further support is given by the fact that normal visual fields are always given with a continuous and smooth isoptre, free of nasal notches, and at monocular gaze straight ahead, the nose is not marked.

Regarding fixation effort due to intrinsic resistance to eye movement during the experiment, the $25^{\circ}$ lateral turn is towards the orbital axis, which implies relative muscle relaxation, whereas nasal gaze fixation is exerted against extraocular muscle tonus, and with a possible fatiguing effect during the recording in a direction possibly conceived as awkward. This seemed to hold even more for the unfamiliar up- and downwards shifts of fixation, where test recordings appeared more variable. Accordingly, for this presentation, the nasal issue was selected as the most unambiguous test situation.

Infant age establishes the visual field: Experience from dense congenital cataracts has indicated the importance of clear imaging at least until age 12-18 weeks for the central retina's subsequent potential to develop DNA-coded visual acuity. A parallel course might be valid for the visual field, presupposing that normal optical access to the posterior pole and the retinal mid-periphery is mandatory. A retinal area for "full field" might thus be scheduled within a few months; its size, however, is probably partly influenced by that period's stronger refraction on behalf of the cornea and lens, and combined with programmed infantile sensory maturation patterns [2-6]. A Norwegian study on normal kinetic Goldmann perimetry in adults showed that individual visual field borders do differ, as also expressed by the samples' uniform standard deviations around an approximated semi-oval averaged borderline [7]. Crosssectional comparisons over adult age further indicated that this is usually constant, even towards old age, provided there is no ocular disease the shape is smooth and without obvious notches or other deviations [7].

Contrary to what holds for establishing early central visual parameters, the literature on visual field development in infants appears scant [4]. A general statement merely emphasizes that fields are "just narrow" soon after birth, particularly towards the nasal side of visual space. In a 1992 study based on automated behavioural perimetry, Lewis and Maurer reported tentative visual field limits of $0^{\circ}$ nasally and $30^{\circ}$ temporally at the age of 2 months, and $15^{\circ}$ and $60^{\circ}$ at 3 months, and close to the adult dimensions $\left(60^{\circ}\right.$ and $90^{\circ}$, respectively) from the age of $6-9$

Fledelius HC | Volume 1; Issue 1 (2020) | JOAR-1(1)-004 | Research Article

Citation: Fledelius HC. The Nasal Coastline of Traquair's Island: The Influence of Gaze Direction on the Recorded Nasal Visual Field. J Ophthalmol Adv Res. 2020;1(1):1-6.

DOI: http://dx.doi.org/10.46889/JOAR.2020.1104 
months [3]. The key factors seemed to be experience gained from visual input combined with the postnatal maturation of the retina and visual pathway, and not the external anatomic limitations possibly set by the otherwise flat facial contours of the infant [3,6,8-11].

\section{Conclusions}

Our pilot test based on large-object kinetic Goldmann perimetry in healthy individuals aged 12-59 years indicated that the span of the nasal visual field did not increase as a response to bypassing the optic obstacle in visual space made up by the nose. Traquair's Island of vision just maintained its size; more beach was not added with a temporal shift of fixation. The hypothesis is that, as a parallel to early data on visual acuity and contrast sensitivity, the definitive size of the visual field is formed during the first 6-9 months of life. This is probably independent of the anterior facial anatomy, as otherwise classically claimed in several textbooks [8-11].

The following questions remain:

1. Do normal visual fields generally involve a fixed part of the posterior retina, as possibly established during a newborn's early stabilization of vision, by way of functional circuitry between the retina and the brain, and possibly retained for a lifetime?

2. In contrast to classic teleology, do we have anterior retinal receptors that are never used, at least not for visual purposes, and are therefore not available due to advanced ex anopsia or other suppressing mechanisms?

\section{References}

1. Traquair HM. An introduction to clinical perimetry. London: Henry Kimpton. 1948;5:70-85.

2. Johnson SP. Development of the visual system. In: Rubenstein JLR, Rakic P, editors. Neural circuit development and function in the brain. Academic Press. 2003;3:249-69.

3. Lewis TL, Maurer D. The development of the temporal and nasal visual fields during infancy. Vision Res. 1992;32:903-11.

4. Sprague Eustis H, Guthrie ME. Postnatal development. In: Wright KW, Strube YJ, editors. Pediatric ophthalmology and strabismus. New York: Oxford University Press. 2012;45-59.

5. Ikeda H, Jacobson SG. Nasal field loss in cats reared with convergent squint: behavioural studies. J Physiol. 1977;270:367-81.

6. Maurer D, Lewis TL. A physiological explanation of infants early visual development. Can J Psychol. 1979;33:232-49.

7. Egge K. The visual field in normal subjects. Acta Ophthalmol. 1984;169:10-6.

8. Duke-Elder S. Textbook of ophthalmology. London: Henry Kimpton. 1938;4:903-17.

9. Lundsgaard E. Lærebog i fysiologi. Copenhagen: Nyt Nordisk Forlag, Arnold Busck; 1954;7:691-5.

10. Hughes B. The visual fields. Oxford: Blackwell. 1954;15-20.

11. Kestenbaum A. Clinical methods of neuro-ophthalmic examination. New York: Grune \& Stratton. 1946;318.

Fledelius HC | Volume 1; Issue 1 (2020) | JOAR-1(1)-004 | Research Article 